\title{
The Guidelines of Human Resource Development to Achieving Capability in Sustainability Leadership: A Case Study in Thailand
}

\author{
Aniwat Kaewjomnong ${ }^{1}$ and Pakapun Skunmun ${ }^{2}$ \\ ${ }^{1}$ International College and Faculty of Economic and Business Administration, Thaksin \\ University, Thailand \\ ${ }^{2}$ International College, Thaksin University, Thailand \\ 1 anthonythai8@ hotmail.com
}

\begin{abstract}
This research aimed to study the concept of human resource development in small and medium enterprises (SMEs) in Thailand and to study the guidelines of human resource development to achieve capability in sustainability leadership. This research was qualitative research. The instrument for research consisted of an interview forms for the qualitative research. The key informants for the study included 10 lectures in university and 10 entrepreneurs' in SMEs in Songkhla Province, Thailand. Purposive sampling was used to find sample group and major data source. The data were analyzed using the content analysis. The results of the study indicated that the human resource development in Thailand need to focus on the attitude, leadership, using of technology and innovation, creativity, foreign languages, human relations, and administrative skills. The capability in sustainability leadership concept is the human resource development in the organization in order that individuals are aware of what they are doing in the organization. The guidelines of human resource development to achieve capability in sustainability leadership is required to make individuals understand and know more about themselves by practicing confidence and expression with the leadership.
\end{abstract}

Keywords: Human Resource Development, Small and Medium Enterprises, Sustainability Leadership

\section{Introduction}

Thailand has increasingly given priority to the development of small and medium enterprises (SMEs) of all types, as can be seen that from 2016 onwards, the government has fully moved forward in the business plan adjustment project and increase the capability of SMEs especially the development of main capability and capability in leadership of Business Entrepreneurs to create the strength that make the business be ready in the competition and be able to support the approaching of ASEAN Economic Community and continue to 2018 that all the government 
agencies that are responsible for pushing and supporting SMEs will have to conduct the working plan for developing and assistance to empower SMEs to enhance their capabilities in every areas to be ready for the ASEAN Economic Community and lead the country onto stability, wealth, and sustainability in the future.

In Songkhla, Thailand, which is a hub of business, in many areas can strongly connect to other provinces in Thailand as well as Malaysia and Singapore in social perspective which is an important resource and infrastructure to support all aspects. Therefore, conducting the SMEs business is outstanding. The sector that economically succeed is rubber industry and rubber processing. The important sector that socially succeed is fisheries industry and fish market and the high important sector and culturally succeed by having a great variety as the presentation of the culture in the products and inherit the local wisdom such as the weaving industry, making dessert, and making Zebra dove cage[1].

From the data gathering related to the success to conduct SMEs in Thailand found that one of the factors is leadership. Especially, when businesses have to compete to each other to support the ASEAN Economic Community. Human resources in business organizations must have greater leadership capabilities than in the past and must have sustainability[2]. Therefore, we must urgently accelerate the development of human resources in SMEs. Researcher have found that the successfully way of human resource development in business organizations is to accelerate the development of capability in sustainability leadership must be successful, accelerating the development of sustainable leadership capabilities as the success in this issue will lead the businesses to competition that support the ASEAN Economic Community and find the success in the future.

Business executives strongly agreed that leadership should be applied in business management[3]. In particular, supportive leadership should be sued primarily in business management. In addition, leadership of business entrepreneurs was correlated with success in business management.

From all reasons and importance above, cause researcher to interest in doing research in the topic of "The guidelines of human resource development to achieving capability in sustainability leadership, a case study in Thailand". The results of the research will be benefits to human resource development in SMEs to ensure sustainability leadership, including private organizations that have to have capability in sustainability leadership development model so that the information will be used in human resource development and evaluate success of human resource development in the organization

\section{Method}

This research is qualitative, data collection from SMEs entrepreneurs and academicians in Songkhla Province, Thailand. The data collected from interviews was analyzed using content analysis.

On the content of capability in sustainability leadership, consist of motivation ability to achieve in duty, the relationship in working, personal attributes, management and leadership[4];[5];[6].

The key informants were 10 SMEs entrepreneurs and staff working in SMEs in Songkhla province, Southern of Thailand that registered with the Department of Commercial Development office, Songkhla, Thailand, by using a specific sampling in the first stage and then select from one's own preference. Including academicians who are involved in leadership development in business organizations from higher education institutions, the amount of 10 people. The total key informants for the research were 20 people. 
Tools in doing qualitative research is a Semi-structured interview. The researcher designed the interview to be relevant to human resource development, leadership capabilities, and leadership capabilities development techniques. The interview conducted by having conversations for understanding and obtaining the most truthful information by having the research assistant to take notes of the information from the interview, bring to content analysis, and summarize the overall by compiling into new information in written language that is readable and easy to understand, and contain of more clarity.

Primary data collected from interviewing the main informants and secondary data collected from compiling the documents, books, textbooks and related research.

\section{Result}

The results of the gathering of human resource development concepts in SMEs in Thailand, to be leading to create the success in competition to support the ASEAN Economic Community. The data analysis result from the main informants have given the opinion that owner has to develop employees' attitudes in order to accept the change in organizational processes, strengthen the process of recruiting people into the organization, develop creative thinking and innovation in the working, develop leadership to be having knowledge and skills in business, develop communication capabilities in using at least 2 languages, develop the ability to use technology or information in working, develop human relations and socialization at all levels, develop to be a business person with morals and ethics, and develop the capability to better manage the work in the organization.

In summary, the concept of human resource development in SMEs that lead to the success to support the ASEAN Economic Community, business entrepreneurs should develop human resources in the matter of attitude, leadership, using of technology and innovation, creativity, foreign languages, human relations, and administrative skills.

To compile capability in sustainability leadership concept of human resources in SMEs in Thailand. The results of the data analysis showed that the capability in sustainability leadership is the human resource development in the organization in order that individuals are aware of what they are doing in the organization and perform with the leadership behaviors in selfcontrolling to be able to work with the capabilities in themselves, adapting themselves to the organizational culture, Be confident in creative expression. Have a proper self in the work. Use innovation in work. Have having confidence in expression with creativity, be yourself in the right perspective in working, use innovation in working, possess decision making skill, having morals, ethics, and responsibility, having service mind and good relationships with people around, motivate yourself and others, be able to manage the change in the organization, be a good coordinator, and work as a team and so on.

Guidelines for Human Resource Development to achieve capability in sustainability leadership in SMEs in Thailand. The results of the data analysis revealed that the practice is required to make individuals understand and know more about themselves by practicing confidence and expression with the leadership. After then, practice individuals to develop their capability in self-controlling to adapt themselves in the organization, to be able to use creativity and innovations in working and making decision, etc. Then practice to see the importance of the surrounding society by meeting with people who are involved with the organization, practice to be having public mind and conduct the social responsibility and so on, and practice to manage the relationship skills with others by motivating others, manage the changes in the organization, be assigned as a coordinator and be able to work as a team and so on. In summary,. 


\section{Discussion}

The results of the gathering of human resource development concept in SMEs in Thailand that lead to creating success in competition that support the ASEAN Economic Community. The business entrepreneurs should develop human resources in terms of attitude, leadership, usage of technology and innovation, creativity, and foreign languages, building the human relations, the research found that the human resource development in the 21 st century of Thailand such as the development of capability, the development of creativity, foreign language communication skill, usage of information technology skills and good management skills[7].

The results of the gathering of capability in sustainability leadership concept of human resource in SMEs in Thailand is the expression of self-control behaviors, be able to adapt yourself to the change, have self-confidence, creativity, properly be yourself, apply innovation in working, possess decision making skill, having morals, ethics, and responsibility, having service mind and good relationships with people around, motivate yourself and others, be a good coordinator, and work as a team and so on. All be in the same direction has presented the concept of sustainable leadership capacity development through the practice of self-understanding, selfcontrol, creative thought, see the importance of all people in the society, be a good coordinator and work as a team[6].

Human Resource Development approach to achieve capability in sustainability leadership in SMEs in Thailand by practicing individuals to understanding and know themselves, practice individuals to have the capability in managing their thoughts, practice to see the importance of the society, and practice to be able to manage the relationship skills with others, the research found that the practice of Oishi Trading Co., Ltd. employees has the core competencies that are needed such as the ability to manage the work in their duty, in the perspective of human relations and working as a team, intelligence and thoughts, and leadership and so on[8].

\section{Conclusion}

The guideline that SMEs in Thailand should apply in human resource development to achieve success in capability in sustainability leadership, such as practice for individuals to be able to understand themselves and to know themselves, practice for individuals to have the capability in managing their thoughts, practice to see the importance of society and practice to manage the relationship skills with others

\section{Acknowledgements}

Researcher would like to thank you everyone for completion of this research, especially International College and Faculty of Economics and Business Administration Thaksin University with supported a fund for research result presentation. Southern Consultants Business Association (SCA) which permitted the researcher for seminar participation and business opinion survey, the Committee of AFBE Academic Conference that paid attention and permitted researcher for this research proposed for international academic conference.

\section{References}

[1] "Office of Small and Medium Enterprises Promotion," dalam Thailand: Roles in Economic, Social and Culture, Bangkok: OSMEP, 2010.

[2] A. Kaewjomnong, "Problems of Small Enterprise Operators with Readiness in Participation in the ASEAN Economic Community: Cased Study of Phatthalung Province," J. Bus. Adm. Assoc. Priv. High. Educ. Inst. Thail., vol. 4, no. 2, hlm. 77-88, 2016. 
[3] A. Kaewjomnong, "Leadership with Success of SMEs in Entering the ASEAN Economic Community: A Case Study of Songkhla," J. Bus. Adm. Assoc. Priv. High. Educ. Inst. Thail., vol. 7, no. 2, hlm. 39-57, 2018.

[4] L. M. Spenser dan M. Spencer, Competence at Work. The United States of America: John Wiley \& Sons, 1993.

[5] H. A. Seyal dan M. N. Rahman, "Testing Bass\&Avolio Model of Leadership in Understanding ERP Implementation among Bruneian SMEs,” J. Organ. Manag. Stud., vol. 2014, hlm. 1-18, 2014.

[6] J. Blewitt, Understanding Sustainable Development, 2nded ed. New York: Routledge, 2015.

[7] T. Thongjuea dan P. Thummake, "The Guidelines for Human Resource Development in the 21 Century According to Educational Dimension," J. MCU Peace Stud., vol. 5, no. 3, hlm. 389-403, 2017.

[8] P. Phuangpricha, A Study of Professional Competencies for Employee of Oishi Trading Company Limited. Thesis, Master of Science in Human Resource Development and Organization (HROD). Bangkok: National Institute of Development Administration (NIDA, 2007. 